\title{
Contact Element Method with Two Relative Coordinates and Its Application to Prediction of Strip Profile of a Sendzimir Mill
}

\author{
Hai-liang YU, ${ }^{1)}$ Xiang-hua LIU1) and Gyoo-Taek LEE ${ }^{2)}$ \\ 1) The State Key Laboratory of Rolling and Automation, Northeastern University, Liaoning, Shenyang 110004 , China. \\ E-mail: yuhailiang1980@tom.com 2) POSCO Technical Research Laboratories, Pohang 545-090, Korea.
}

(Received on February 5, 2007; accepted on April 27, 2007)

\begin{abstract}
A new numerical method, Contact Element Method with Two Relative Coordinates, has been developed. The main features of this method are that element meshing depends on the contact length between rolls or between the work roll and the strip, and that each element has two relative coordinates based on two separate contact objects. With this method, a program code "Setup Models for Sendzimir Mill" (SM4SM) has been developed for prediction of the strip profile of a 20-high Sendzimir mill with double AS-U-Roll systems. The strip profiles are predicted under various rolling conditions, such as the positions of AS-U racks, the 1st intermediate roll (IMR) shift and taper slope \& length, the roll J profile and the coefficient of friction, etc.
\end{abstract}

KEY WORDS: contact element method; strip profile; 20-high mill; numerical method.

\section{Introduction}

High rigidity 20-high mills with small-diameter work rolls are widely used to roll stainless steel sheets, silicon sheets, Al foils, etc. So far, there have been more than 400 20-high mills in the world. However, it is difficult to make a theoretical analysis of the complex rolls system. Scheider and Werners ${ }^{1)}$ studied the on-line modeling and optimizing of a 20-high mill; Hara et al. ${ }^{2)}$ researched the shape controllability for the quarter buckles of strip in a 20-high mill; Berger et l. $^{3)}$ introduced the advanced 20-high mill technology; Peter et al. ${ }^{4)}$ introduced the high tensile, light gauge rolling with 20 -high reversing cold rolling. Some other researchers ${ }^{5,6)}$ used the Influence Function Method (IFM) to predict the strip profile of a Sendzimir mill.

It is significant to predict the strip profile in the flat rolling processes. Kim et ll $^{7)}$ developed a model of the integrated FE process to predict the strip profile in a 4-high mill. And 5 kinds of roll flattening models were used to determine the roll flattening by Zhou et al. ${ }^{8}$. Xu et al. ${ }^{9}$ developed the "Influence Efficiency Calculation Software" which was used to predict the strip profile with various bending force of the work roll in a 4-high mill. Jiang et al. ${ }^{10)}$ analyzed the strip profile in cold rolling by Finite Element Method (FEM). Yuen et al. ${ }^{11)}$ developed a previous model for the roll stack deflection and provided a new formulation to analyze the strip flatness. Liu and Lee ${ }^{12)}$ developed a mathematical model for a cold and temper rolling process of the thin strip using the IFM, and discussed the relationship between the shape of the roll profile and the rolling force. Combining the IFM with the variational method to solve the lateral flow of metal, the flatness and profile of the strip during cold rolling were simulated by Li and Lian. ${ }^{13)}$

There are many numerical methods which can be used to analyze the problems existing in the rolling processes. The FEM $^{10,14,15)}$ is widely used for analyzing these problems, such as the deformation, the microstructure, etc. But, it is difficult to systemically analyze the 20-high rolling problems, especially the strip profile because of the complex contact conditions with 3-D models. Finite Differential Method $(\mathrm{FDM})^{16)}$ is widely used to analyze the thermal field on account of easy understanding and programming. However, it is seldom used to analyze the deformation problems in the rolling process. The IFM, ${ }^{5,6,13,17,18)}$ which doesn't need to assume the rolling pressure, the pressure between rolls and the roll work curve distribution, is widely used to predict the strip profile in the rolling process.

The contact element method with two relative coordinates (CEM) is a discrete method similar to the IFM. This paper introduces the main characteristics of this method and the deducing of a CEM matrix of a Sendzimir mill. With this method, a program code "Setup Models for Sendzimir Mill" (SM4SM) for the prediction of the strip profile has been developed for the 20-high Sendzimir mill with double AS-U-Roll systems, and a series of influence factors on the strip profile are analyzed.

\section{Analytical Method and Mathematical Models}

\subsection{Contact Element Method with Two Relative Coor- dinates}

Figure 1 shows the element meshing between the work roll and the strip, and between the work roll and the 1 st intermediate roll (IMR). Two relative coordinates are established for each element depending on the two contact objects respectively. For elements between the strip and the work roll, one relative coordinate depends on the strip width, and the other depends on the barrel length of the 


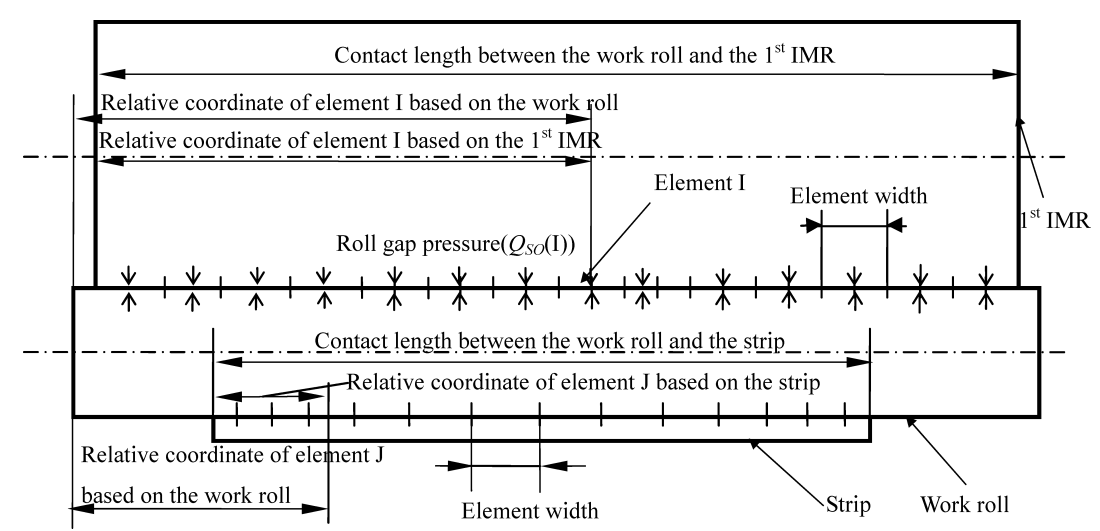

Fig. 1. Element meshing.

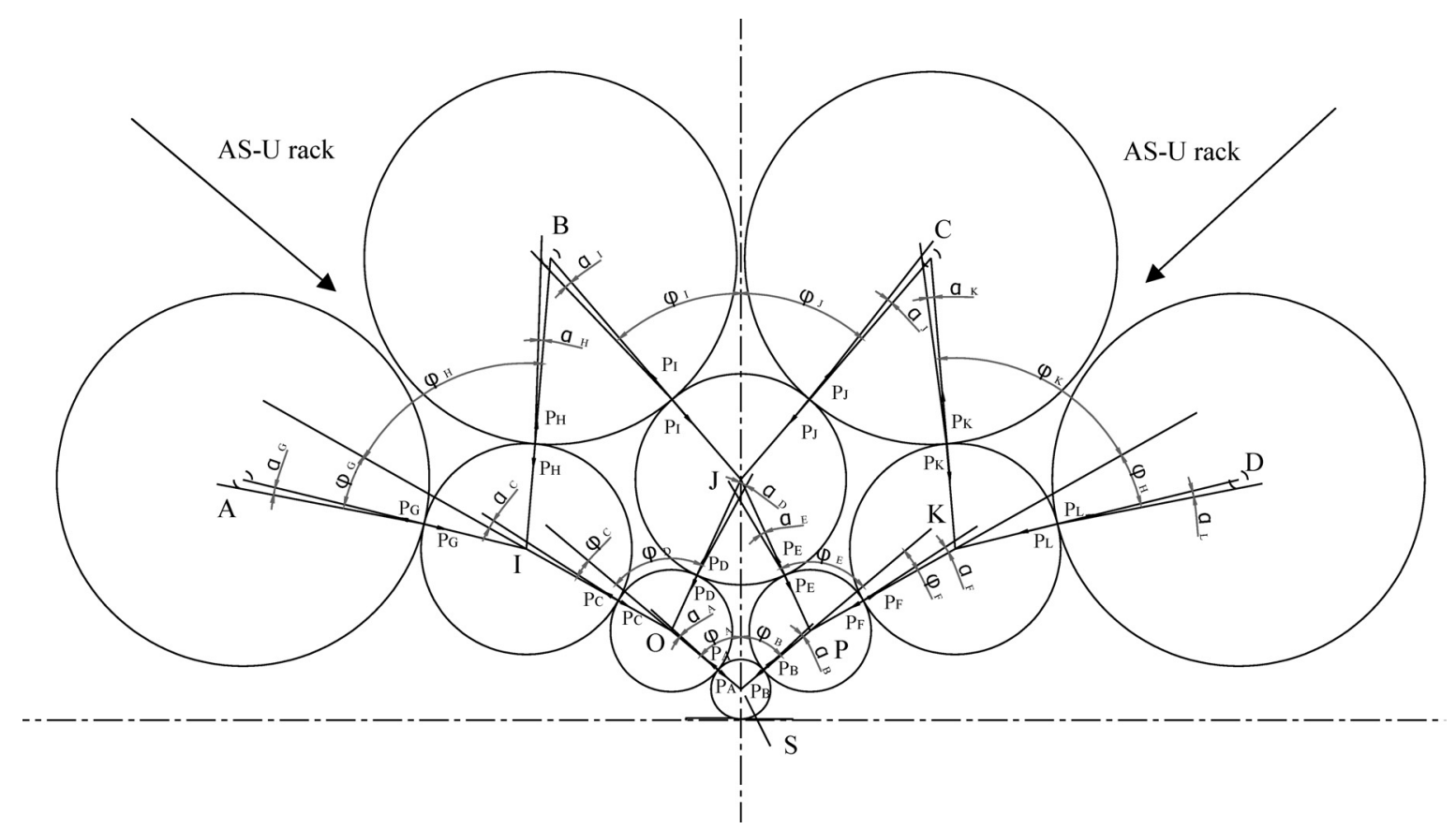

Fig. 2. Friction angle and acting force in a 20-high Sendzimir mill.

work roll. The same method is used for dealing with the elements in the contact zone between rolls.

\section{1) Width of Elements}

The width of elements depends on the contact length between rolls or between the work roll and the strip, and does$n$ 't depend on the barrel length of rolls. Because the contact lengths between rolls or between the work roll and the strip are different, the width of elements between different contact objects doesn't keep constant. The element width in the contact zone between objects can be calculated by Eq. (1), where $W_{X}>W_{Y}$. From the equation, $W_{S S}$ and $W_{X Y}$ can be calculated.

$$
W_{X Y}=\frac{W_{Y}}{\mathrm{~N}}
$$

\section{2) Relative Coordinates of Elements}

Equation (2) shows the relative coordinates of element I in the contact zone between objects $\mathrm{X}$ and $\mathrm{Y}$, assuming $W_{X}>W_{Y}$. From the equation, $C_{S S}$ and $C_{X Y}$ can be calculated.

$$
\begin{aligned}
& C_{X Y}(\mathrm{I})=\left(W_{X}-W_{Y}\right) / 2.0+(\mathrm{I}-0.5) W_{X Y} \\
& C_{Y X}(\mathrm{I})=(\mathrm{I}-0.5) W_{X Y}
\end{aligned}
$$

3) Pressure on Elements

There are $\mathrm{N}$ elements in the contact zone between objects $\mathrm{X}$ and $\mathrm{Y}$, and the rolling pressure and the pressure between rolls on each element are unknown, which are named $Q_{X Y}$ (Rolling pressure are named $Q_{S S}$ ).

\section{4) Deformation Coordination Equation}

Two objects at the contact position have the equal displacements during the deformation process, so elements for two relative coordinates in the rolls system have equal displacement. According to this idea, the deformation coordination equation of element in $C_{X Y}(\mathrm{I})$ between objects $\mathrm{X}$ and $\mathrm{Y}$ can be described by the following equation.

$$
D_{X}\left(C_{X Y}(\mathrm{I})\right)=D_{Y}\left(C_{Y X}(\mathrm{I})\right) \text {. }
$$

\subsection{CEM Matrix for a 20-High Sendzimir Mill}

Figure 2 shows the rolls distribution and the acting 
force $^{19)}$ in rolls system of a Sendzimir mill. For the sake of establishing the CEM matrix of the Sendzimir mill, some simplified mathematical models are employed, such as M. D. Stone's formula, ${ }^{19)}$ Hertz's equation, ${ }^{17)}$ Hitchcock equation, ${ }^{17)}$ the simply beam deflection model ${ }^{20}$ ) (as shown in Eq. (4)), etc.

$$
\begin{aligned}
& y(x)=g\left(F, l_{1}, L, I_{X}, x\right) \\
& = \begin{cases}-\frac{F l_{2} x}{6 E I_{Z} L}\left(x^{2}-L^{2}+l_{2}^{2}\right) & (0 \leq x<a) \\
-\frac{F l_{2} x}{6 E I_{Z} L}\left(x^{2}-L^{2}+l_{2}^{2}\right)+\frac{F l_{2}}{6 E I_{Z}}\left(x-l_{1}\right)^{3} & (a \leq x \leq L)\end{cases}
\end{aligned}
$$

During the deformation process, the roll deformation can be divided into two parts: the roll deflection and the roll flattening. Figure 3 shows the deformation between the rolls $\mathrm{S}$ and $\mathrm{O}$, where the deflection of the roll $\mathrm{S}$ is affected by $Q_{S S}, Q_{S O}$ and $Q_{S P}$. From Eq. (4), the deflection of the roll $\mathrm{S}$ affected by $Q_{S S}$ in $C_{S O}$ (I) can be calculated by Eq. (5).

$$
\begin{aligned}
D_{S_{-} Q_{S S}} & \left(C_{S O}(\mathrm{I})\right) \\
= & \mathrm{g}\left(Q_{S S}(1) \times W_{S S} \times \cos \left(\varphi_{A}+v\right), C_{S S}(1), W_{S}, I_{S}, C_{S O}(\mathrm{I})\right) \\
& +\mathrm{g}\left(Q_{S S}(2) \times W_{S S} \times \cos \left(\varphi_{A}+v\right), C_{S S}(2), W_{S}, I_{S}, C_{S O}(\mathrm{I})\right) \\
& +\cdots+\mathrm{g}\left(Q_{S S}(\mathrm{~N}-1) \times W_{S S}\right. \\
& \left.\times \cos \left(\varphi_{A}+v\right), C_{S S}(\mathrm{~N}-1), W_{S}, I_{S}, C_{S O}(\mathrm{I})\right) \\
& +\mathrm{g}\left(Q_{S S}(\mathrm{~N}) \times W_{S S} \times \cos \left(\varphi_{A}+v\right), C_{S S}(\mathrm{~N}), W_{S}, I_{S}, C_{S O}(\mathrm{I})\right) \\
= & Q_{S S}(1) \times W_{S S} \times \mathrm{g}\left(\cos \left(\varphi_{A}+v\right), C_{S S}(1), W_{S}, I_{S}, C_{S O}(\mathrm{I})\right) \\
& +Q_{S S}(2) \times W_{S S} \times \mathrm{g}\left(\cos \left(\varphi_{A}+v\right), C_{S S}(2), W_{S}, I_{S}, C_{S O}(\mathrm{I})\right) \\
& +\cdots+Q_{S S}(\mathrm{~N}-1) \times W_{S S} \\
& \times \mathrm{g}\left(\cos \left(\varphi_{A}+v\right), C_{S S}(\mathrm{~N}-1), W_{S}, I_{S}, C_{S O}(\mathrm{I})\right) \\
& +Q_{S S}(\mathrm{~N}) \times W_{S S} \times \mathrm{g}\left(\cos \left(\varphi_{A}+v\right), C_{S S}(\mathrm{~N}), W_{S}, I_{S}, C_{S O}(\mathrm{I})\right) \\
= & \sum_{\mathrm{J}=1}^{\mathrm{N}} Q_{S S}(\mathrm{~J}) \times W_{S S} \times \mathrm{g}\left(\cos \left(\varphi_{A}+v\right), C_{S S}(\mathrm{~J}), W_{S}, I_{S}, C_{S O}(\mathrm{I})\right) \\
= & \sum_{\mathrm{J}=1}^{\mathrm{N}} Q_{S S}(\mathrm{~J}) \times W_{S S} \times \mathrm{g}\left(\cos \left(\varphi_{A}+v\right), C_{S S}(\mathrm{~J}), \Phi_{S O}\right) \ldots \ldots \ldots . .(5)
\end{aligned}
$$

With the same method, the deflection of the roll $\mathrm{S}$ affected by $Q_{S O}$ and $Q_{S P}$ in $C_{S O}(\mathrm{I})$ can be calculated by Eqs. (6) and (7).

$$
\begin{aligned}
& D_{S_{-} Q_{S O}}\left(C_{S O}(\mathrm{I})\right) \\
& =\sum_{\mathrm{J}=1}^{\mathrm{N}} Q_{S O}(\mathrm{~J}) \times W_{S O} \times \mathrm{g}\left(-\cos \left(\alpha_{A}\right), C_{S O}(\mathrm{~J}), \Phi_{S O}\right) \ldots(6) \\
& D_{S_{-} Q_{S P}}\left(C_{S O}(\mathrm{I})\right) \\
& =\sum_{\mathrm{J}=1}^{\mathrm{N}} Q_{S P}(\mathrm{~J}) \times W_{S P} \times \mathrm{g}\left(-\cos \left(\varphi_{A}+\varphi_{B}+\alpha_{B}\right), C_{S P}(\mathrm{~J}), \Phi_{S O}\right)
\end{aligned}
$$

From Hertz's equation, the flattening of the roll $\mathrm{S}$ in $C_{S O}(\mathrm{I})$ between rolls $\mathrm{S}$ and $\mathrm{O}$ is shown in Eq. (8).

$$
R F_{S O}\left(C_{S O}(\mathrm{I})\right)=Q_{S O}(\mathrm{I}) \times F_{S O}(\mathrm{I})
$$

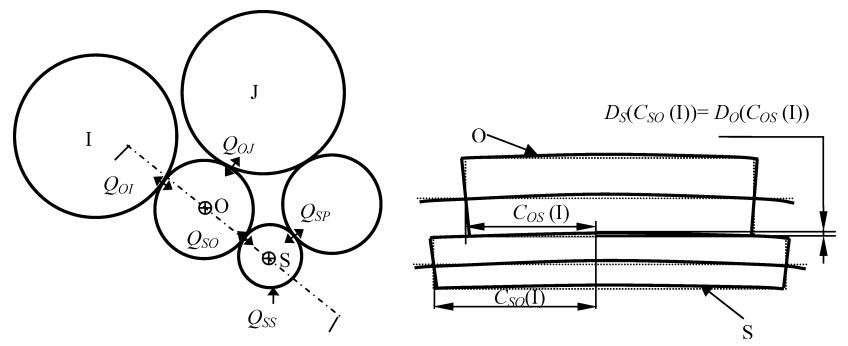

Fig. 3. Deformation between the rolls $\mathrm{S}$ and $\mathrm{O}$.

So the deformation of the roll $\mathrm{S}$ in $C_{S O}$ (I) between the rolls $\mathrm{S}$ and $\mathrm{O}$ can be calculated by Eq. (9).

$$
\begin{aligned}
& D_{S}\left(C_{S O}(\mathrm{I})\right) \\
& =D_{S_{-} Q_{S S}}\left(C_{S O}(\mathrm{I})\right)+D_{S_{-} Q_{S O}}\left(C_{S O}(\mathrm{I})\right) \\
& +D_{S_{-} Q_{S P}}\left(C_{S O}(\mathrm{I})\right)+R F_{S O}\left(C_{S O}(\mathrm{I})\right) \\
& =\sum_{\mathrm{J}=1}^{\mathrm{N}}\left(Q_{S S}(\mathrm{~J}) \times W_{S S} \times \mathrm{g}\left(\cos \left(\varphi_{A}+v\right), C_{S S}(\mathrm{~J}), \Phi_{S O}\right)\right. \\
& +Q_{S O}(\mathrm{~J}) \times W_{S O} \times \mathrm{g}\left(-\cos \left(\alpha_{A}\right), C_{S O}(\mathrm{~J}), \Phi_{S O}\right) \\
& \left.+Q_{S P}(\mathrm{~J}) \times W_{S P} \times \mathrm{g}\left(-\cos \left(\varphi_{A}+\varphi_{B}+\alpha_{B}\right), C_{S P}(\mathrm{~J}), \Phi_{S O}\right)\right) \\
& +Q_{S O}(\mathrm{I}) \times F_{S O}(\mathrm{I})
\end{aligned}
$$

In Fig. 3, the deflection of the roll $\mathrm{O}$ is affected by $Q_{S O}$, $Q_{O I}, Q_{O J}$, and its deformation in $C_{O S}(\mathrm{I})$ between the rolls $\mathrm{O}$ and $\mathrm{S}$ can be calculated by Eq. (10) which is similar to Eq. (9).

$$
\begin{aligned}
& D_{O}\left(C_{O S}(\mathrm{I})\right) \\
& =D_{S_{-} Q_{S O}}\left(C_{O S}(\mathrm{I})\right)+D_{S_{-} Q_{O I}}\left(C_{O S}(\mathrm{I})\right) \\
& +D_{S_{-} Q_{O I}}\left(C_{O S}(\mathrm{I})\right)+R F_{O S}\left(C_{O S}(\mathrm{I})\right) \\
& =\sum_{\mathrm{J}=1}^{\mathrm{N}}\left(Q_{S O}(\mathrm{~J}) \times W_{S O} \times \mathrm{g}\left(\cos \left(\varphi_{A}\right), C_{O S}(\mathrm{~J}), \Phi_{O S}\right)\right. \\
& +Q_{O I}(\mathrm{~J}) \times W_{O I} \times \mathrm{g}\left(-\cos \left(\varphi_{C}+\alpha_{C}\right), C_{O I}(\mathrm{~J}), \Phi_{O S}\right) \\
& \left.+Q_{O J}(\mathrm{~J}) \times W_{O J} \times \mathrm{g}\left(-\cos \left(\varphi_{D}+\alpha_{D}\right), C_{O J}(\mathrm{~J}), \Phi_{O S}\right)\right)
\end{aligned}
$$

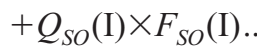

According to Eq. (3), the deformation coordination equation for element I between the rolls S and O (Eq. (11)) can be deduced from Eqs. (9) and (10).

$$
\begin{aligned}
& \sum_{\mathrm{J}=1}^{\mathrm{N}}\left(Q_{S S}(\mathrm{~J}) \times W_{S S} \times \mathrm{g}\left(\cos \left(\varphi_{A}+v\right), C_{S S}(\mathrm{~J}), \Phi_{S O}\right)\right. \\
& +Q_{S O}(\mathrm{~J}) \times W_{S O} \times \mathrm{g}\left(-\cos \left(\varphi_{A}\right), C_{S O}(\mathrm{~J}), \Phi_{S O}\right) \\
& \left.+Q_{S P}(\mathrm{~J}) \times W_{S P} \times \mathrm{g}\left(-\cos \left(\varphi_{A}+\varphi_{B}+\alpha_{B}\right), C_{S P}(\mathrm{~J}), \Phi_{S O}\right)\right) \\
& +Q_{S O}(\mathrm{I}) \times F_{S O}(\mathrm{I}) \\
& =\sum_{\mathrm{J}=1}^{\mathrm{N}}\left(Q_{S O}(\mathrm{~J}) \times W_{S O} \times \mathrm{g}\left(\cos \left(\varphi_{A}\right), C_{O S}(\mathrm{~J}), \Phi_{O S}\right)\right. \\
& +Q_{O I}(\mathrm{~J}) \times W_{O I} \times \mathrm{g}\left(-\cos \left(\varphi_{C}+\alpha_{C}\right), C_{O I}(\mathrm{~J}), \Phi_{O S}\right) \\
& \left.+Q_{O J}(\mathrm{~J}) \times W_{O J} \times \mathrm{g}\left(-\cos \left(\varphi_{D}+\alpha_{D}\right), C_{O J}(\mathrm{~J}), \Phi_{O S}\right)\right) \\
& +Q_{S O}(\mathrm{I}) \times F_{O S}(\mathrm{I}) \quad(1 \leq \mathrm{I} \leq \mathrm{N}) \text {. }
\end{aligned}
$$

In like manner, the deformation coordination equations between the rolls $\mathrm{S}$ and $\mathrm{P}, \mathrm{O}$ and $\mathrm{I}, \mathrm{O}$ and $\mathrm{J}, \mathrm{P}$ and $\mathrm{J}, \mathrm{P}$ and 
$\mathrm{K}, \mathrm{I}$ and $\mathrm{A}, \mathrm{I}$ and $\mathrm{B}, \mathrm{J}$ and $\mathrm{B}, \mathrm{J}$ and $\mathrm{C}, \mathrm{K}$ and $\mathrm{C}$, and $\mathrm{K}$ and $\mathrm{D}$ are established, which are shown in the appendix: Deformation coordination equations between rolls.

From Eqs. (11)-(22), a $12 \mathrm{~N} \times 12 \mathrm{~N}$ matrix could be built, and then the pressure between rolls could be obtained.

\section{Application}

Using the contact element method with two relative coordinates, the program code SM4SM has been developed for the prediction of the strip profile of the Sendzimir mill with double AS-U-Roll systems, which can be used to predict the strip profile under different positions of AS-U racks, 1st IMR shifts and taper slopes \& lengths, initial strip profiles, roll $\mathbf{J}$ profiles, etc. The flow chart of the main program is shown in Fig. 4.

With the SM4SM, the strip profiles are predicted under various rolling conditions. The basic rolling conditions and calculation parameters are shown in Table 1.

In the course of simulation, just some of the parameters are changed each time.

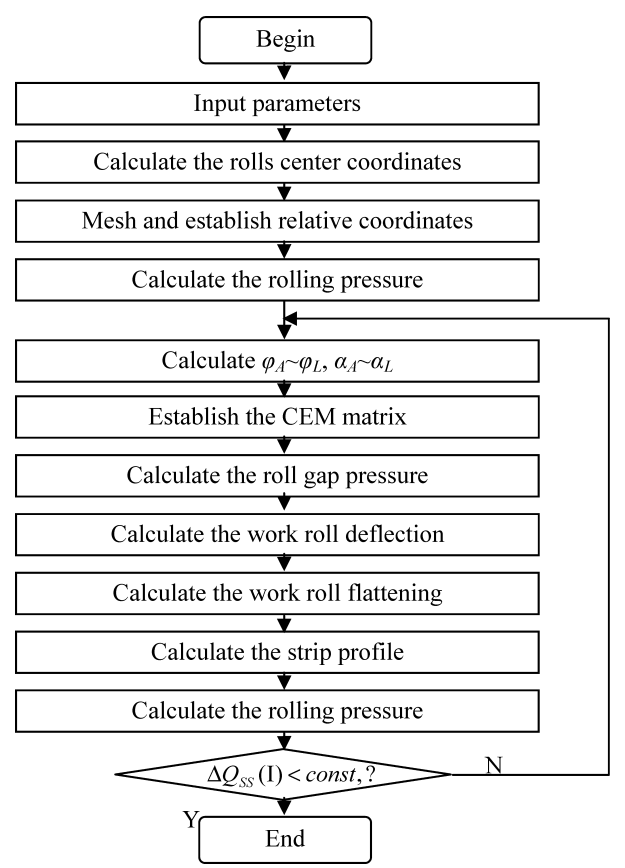

Fig. 4. SM4SM flow chart.

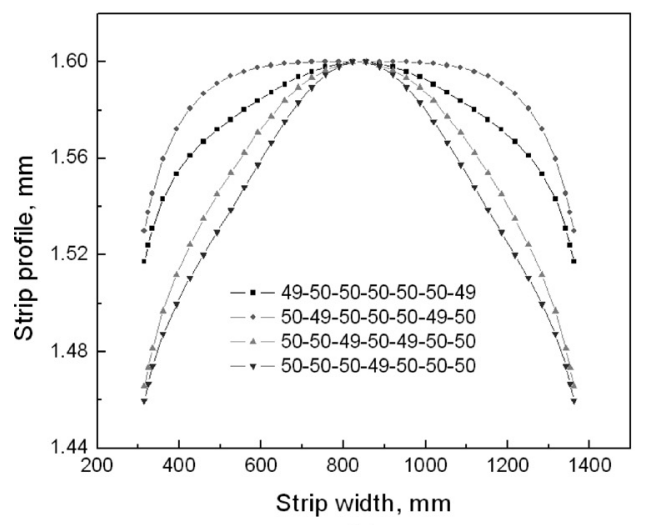

(a)

\section{Results and Analysis}

With the software of SM4SM, the strip profile is able to be predicted under various rolling conditions, such as the position of the AS-U racks, the 1st IMR shift and taper slope \& length, the roll J profile, the reduction ratio, the coefficient of friction, the tension, the entry strip crown, etc.

\subsection{Influence of the Position of the AS-U Racks}

Figure 5 shows the strip profile with the adjustment of the position of the AS-U racks, where N1-N2-N3-N4-N5N6-N7 denotes the position of the AS-U racks 1-7.

Figure 5(a) shows the strip profile under the symmetrical

Table 1. General rolling conditions and parameters.

\begin{tabular}{|c|c|}
\hline Parameters & Value \\
\hline Position of AS-U racks & $49-50-51-50-51-50-49$ \\
\hline $1^{\text {st }}$ IMR shift, mm & 30 \\
\hline $1^{\text {st }}$ IMR taper slope, N/10 000 & 10 \\
\hline $1^{\text {st }}$ IMR taper length, mm & 230 \\
\hline Roll J crown, mm & 0.0 \\
\hline Diameter of rolls $\mathrm{A}, \mathrm{B}, \mathrm{C}$ and $\mathrm{D}, \mathrm{mm}$ & 406.4 \\
\hline Diameter of rolls $\mathrm{I}$, J and $\mathrm{K}, \mathrm{mm}$ & 235.0 \\
\hline Diameter of rolls $\mathrm{O}$ and $\mathrm{P}, \mathrm{mm}$ & 140.0 \\
\hline Diameter of roll $\mathrm{S}, \mathrm{mm}$ & 75.0 \\
\hline Part of barrel length of roll A, B, C and D, mm & 171.0 \\
\hline Space length of roll A, B, C and D, mm & 64.0 \\
\hline Barrel length of roll $\mathrm{I}, \mathrm{J}$ and $\mathrm{K}, \mathrm{mm}$ & 1450.0 \\
\hline Barrel length of roll $\mathrm{O}$ and $\mathrm{P}, \mathrm{mm}$ & 1500.0 \\
\hline Barrel length of roll S, mm & 1677.0 \\
\hline Initial strip thickness, mm & 2.3 \\
\hline Initial strip crown, $\mu \mathrm{m}$ & 40 \\
\hline Initial edge drop of strip, $\mathrm{mm}$ & 30 \\
\hline Initial strip width, $\mathrm{mm}$ & 1050.0 \\
\hline Strip exit thickness, $\mathrm{mm}$ & 1.6 \\
\hline Coefficient of friction & 0.05 \\
\hline Young's modulus of strip, MPa & $2.06 \mathrm{E} 5$ \\
\hline Deformation resistance of strip, MPa & $C(0.001+\varepsilon)^{\mathrm{n}}$ \\
\hline Poisson's ratio & 0.3 \\
\hline Young's modulus of rolls, $\mathrm{MPa}$ & $2.6 \mathrm{E} 5$ \\
\hline Back tension of strip, MPa & 12.0 \\
\hline Front tension of strip, $\mathrm{MPa}$ & 146.0 \\
\hline
\end{tabular}

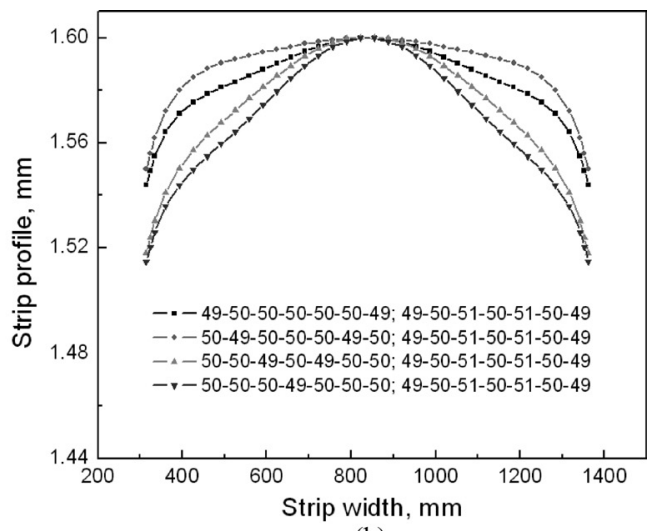

(b)

Fig. 5. Strip profile for various $A S-U$ racks position. 


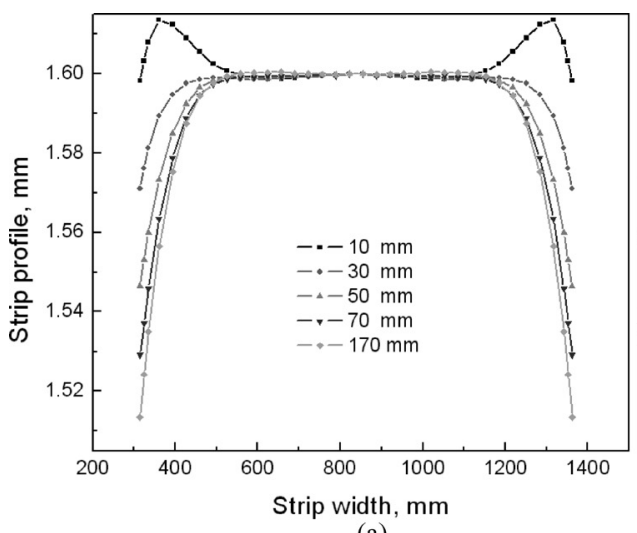

(a)

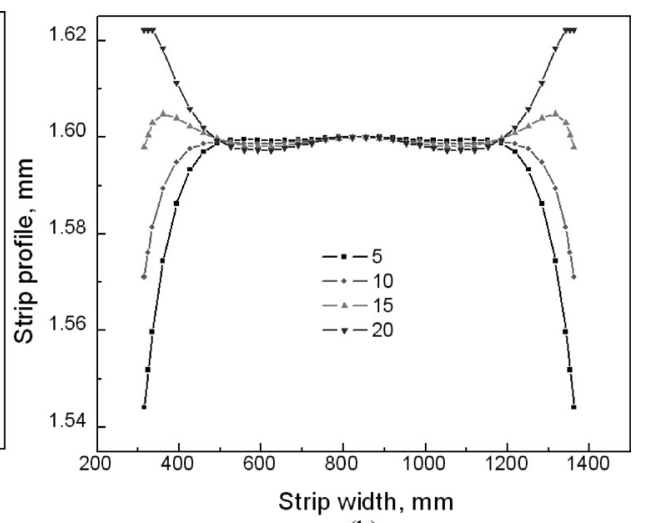

(b)

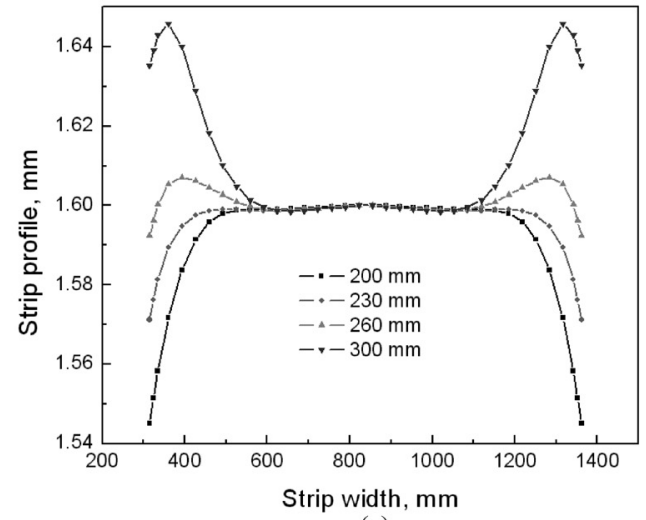

(c)

Fig. 6. Strip profile for different 1 st IMR shift and taper slope \& length.

loading when the position of the AS- $\mathrm{U}$ racks is adjusted from 50 to 49 and the position of the AS-U racks between the rolls $\mathrm{A}$ and $\mathrm{B}$ is identical with that between the rolls $\mathrm{C}$ and $\mathrm{D}$, from which the change of strip profile is clear when the AS-U racks are adjusted. The thicknesses at the strip center are identical because the strip central thicknesses are assumed to equal the strip exit thickness. Adjustment of the 1 st and 7th AS-U racks makes the thickness at the strip edge decrease a little. Adjustment of the 2nd and 6th AS-U racks makes the strip crown change little compared with the adjustment of the 1st and 7th AS-U racks. Adjustment of the 3rd and 5th AS-U racks gets the strip crown to increase clearly. When the 4th AS-U rack is adjusted, the strip profile is similar to that when the 3rd and 5th AS-U racks are adjusted. From the above results, the influence of the 1st, 2nd, 6th, 7th AS-U racks on the strip edge thickness is greater than that on the strip central thickness, and the influence of the $3 \mathrm{rd}$, 4th, 5th AS-U racks on the strip central thickness is clearer than that on the strip edge thickness. So, if the strip edge wave appears, the 1st, 2nd, 6th, 7th AS-U racks should be preferentially adjusted; and if the strip takes on the center wave, the 3rd, 4th, 5th AS-U racks should be preferentially adjusted.

Figure 5(b) shows the strip profile under the symmetrical loading, but the position of AS-U racks between the rolls A and $\mathrm{B}$ is different from that between the rolls $\mathrm{C}$ and $\mathrm{D}$, and just the position of AS-U racks between the rolls A and B is adjusted. Compared Fig. 5(b) with Fig. 5(a), the influence of the position of AS-U racks on the strip profile is similar, but the strip crown of the former is much less than that of the latter.

\subsection{Influence of the 1st IMR Shift and Taper (Slope and Length)}

Figure 6 shows the strip profile under different 1st IMR taper and shift, the taper slope is 10 , the taper length is $230 \mathrm{~mm}$, and the shift is changed in Fig. 6(a); the taper length is $230 \mathrm{~mm}$, the shift is $30 \mathrm{~mm}$, and the taper slope is changed in Fig. 6(b); the taper slope is 10, the shift is $30 \mathrm{~mm}$, and the taper length is changed in Fig. 6(c).

Influence of the 1st IMR shift and taper on the strip profile is mainly assembled near the slab edge. When the 1st IMR shift increases, the strip edge drop increases. As the taper slope increases, the strip edge drop decreases. And as the taper length increases, the strip edge drop decreases. However, if the 1st IMR shift is too little or the taper slope is too large or the taper length is too long, the thickness at the strip edge will be larger than that at the strip center.

\subsection{Influence of the Roll J Profile}

Figure 7 shows the strip profile with various roll $\mathrm{J}$ profiles. As the crown of the roll $\mathrm{J}$ increases, the strip edge drop decreases, and the strip crown decreases. During the rolling process, the small crown of roll $\mathrm{J}$ can be used to control the strip profile and the edge drop. But when the crown of roll $\mathrm{J}$ is too large, the thickness at the strip edge will be thicker than that at the strip center.

\subsection{Influence of the Strip Reduction Ratio}

Figure 8 shows the strip profile with various strip reduction ratios. In the figure, the strip crown increases with the increase of the strip reduction ratio. The main factor is that the rolling pressure increases with the increase of the strip 


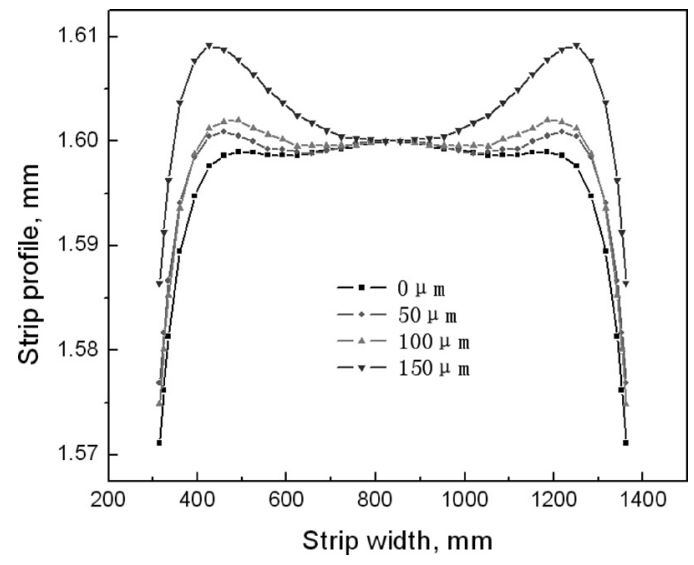

Fig. 7. Strip profile for various roll J profile.

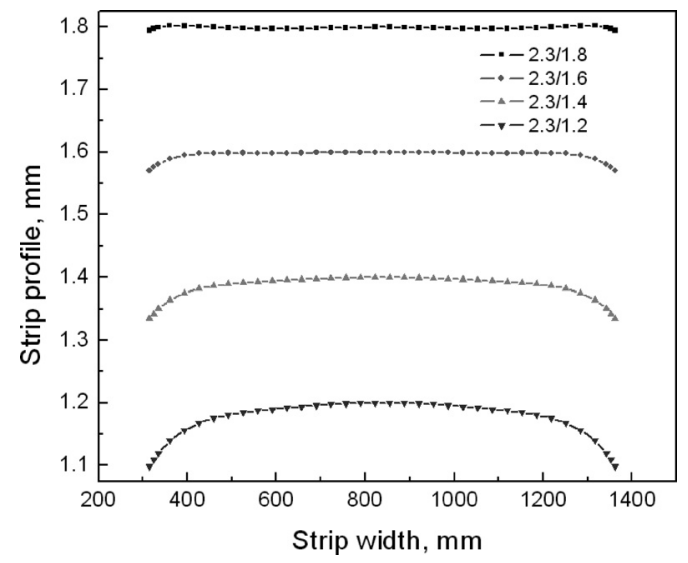

Fig. 8. Strip profile for various strip reduction ratio.

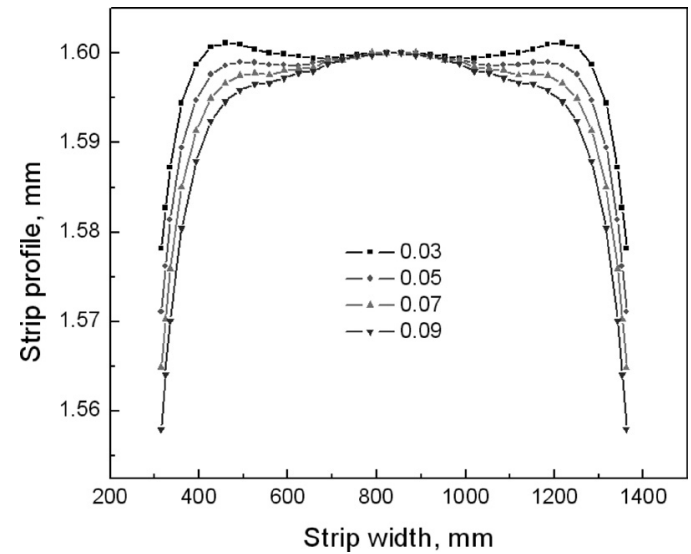

Fig. 9. Strip profile for various coefficient of friction.

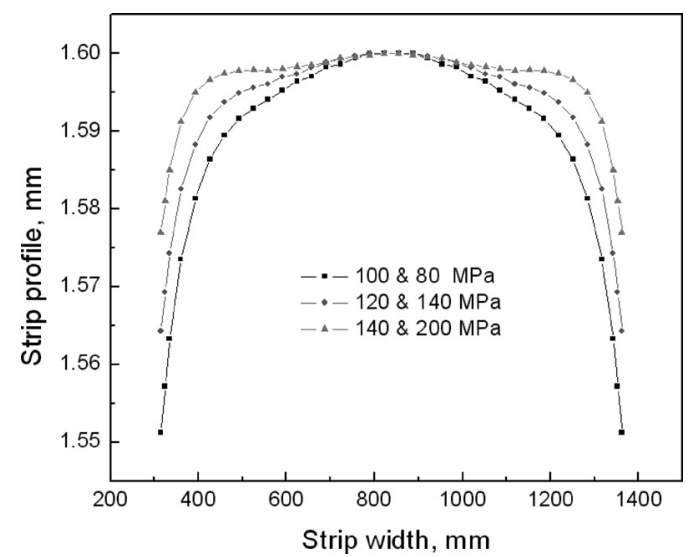

Fig. 10. Strip profile for various tension.

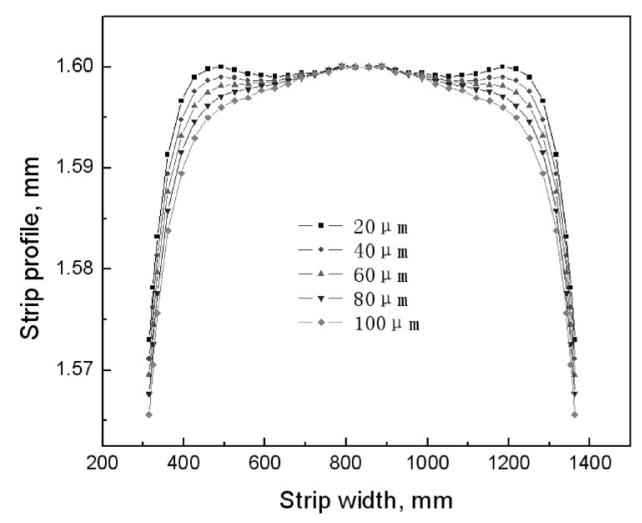

(a)

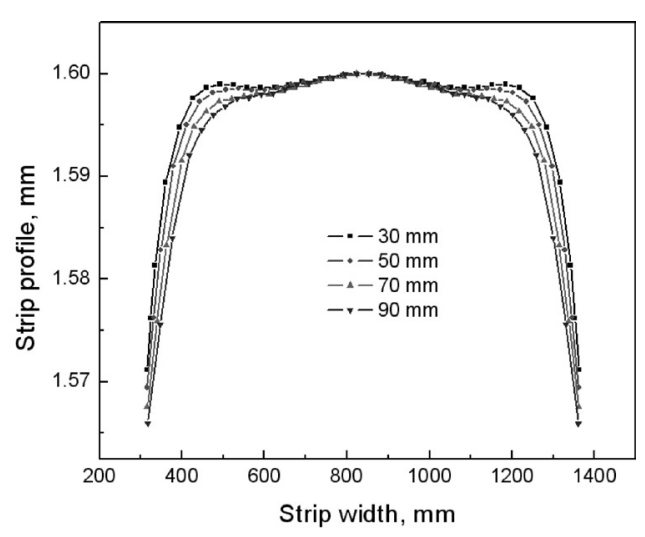

(b)

Fig. 11. Strip profile for various strip entry crowns (a) and strip edge drops (b).

reduction ratio, which makes the rolls deflection and the rolls flattening increase.

\subsection{Influence of the Coefficient of Friction}

Figure 9 shows the strip profile for various coefficients of friction. The strip profile has small change with the change of the coefficient of friction. Meanwhile, the strip crown increases with the increase of the coefficient of friction.

Generally, the coefficient of friction increases, then the rolling pressure increases, which increases the deformation of rolls (both the rolls deflection and the rolls flattening).

\subsection{Influence of the Tension}

Figure 10 shows the strip profile for various tension stresses. As the tension stress increases, the strip crown decreases.

\subsection{Influence of the Strip Entry Profile}

Figure 11 shows the strip profile for various strip entry profiles, such as the strip entry crown and the edge drop length. The edge drop length of strip is $30 \mathrm{~mm}$ and the initial strip crown is changed in Fig. 11(a); the strip entry crown is $60 \mu \mathrm{m}$ in Fig. 11(b). As the strip entry crown increases, the strip exit crown increases, and as the strip edge 

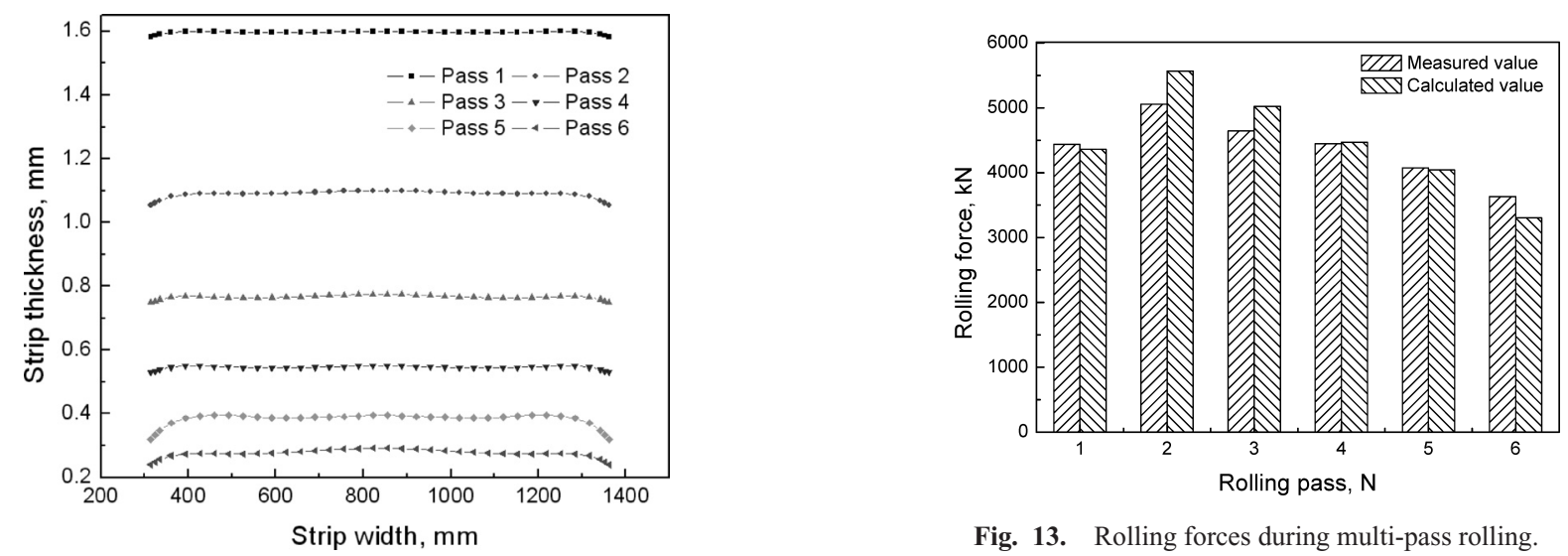

Fig. 13. Rolling forces during multi-pass rolling.

Fig. 12. Strip profile during multi-pass rolling.

Table 2. Rolling conditions during multi-pass rolling.

\begin{tabular}{lcccccc}
\hline & Pass 1 & Pass 2 & Pass 3 & Pass 4 & Pass 5 & Pass 6 \\
\hline Strip entry thickness & 2.3 & 1.6 & 1.1 & 0.775 & 0.55 & 0.395 \\
Strip exit thickness & 1.6 & 1.1 & 0.775 & 0.55 & 0.395 & 0.292 \\
AS-U rack 1 & 49 & 49 & 49 & 49 & 49 & 49 \\
AS-U rack 2 & 50 & 50 & 50 & 50 & 50 & 50 \\
AS-U rack 3 & 51 & 51 & 51 & 51 & 51 & 50 \\
AS-U rack 4 & 50 & 50 & 50 & 50 & 50 & 50 \\
AS-U rack 5 & 51 & 51 & 51 & 51 & 51 & 50 \\
AS-U rack 6 & 50 & 50 & 50 & 50 & 50 & 50 \\
AS-U rack 7 & 49 & 49 & 49 & 49 & 49 & 49 \\
$1^{\text {st }}$ IMR shift & 30 & 20 & 20 & 35 & 10 & 5 \\
$1^{\text {st }}$ IMR taper slope & 10 & 10 & 10 & 10 & 10 & 10 \\
$1^{\text {st }}$ IMR taper length & 230 & 230 & 230 & 230 & 230 & 230 \\
\hline
\end{tabular}

drop length increases, the strip edge drop increases.

\subsection{Prediction of Multi-pass Strip Profiles}

Figure 12 shows the prediction of multi-pass strip profiles for various rolling conditions as shown in Table 2. The strip profile in the former pass is used as the initial strip profile of the next pass. Meanwhile, the rolling forces of the calculated results are compared with that of the measured results, which are shown in Fig. 13. From the figure, the differences between the calculated results and the measured results are small, and the CEM is an effective method for analysis of the strip profile in the Sendzimir mill.

\section{Conclusions}

(1) The basic theory and thought of the contact element method with two relative coordinates is introduced, and the main equations for the prediction of the strip profile in a 20-high mill are deduced.

(2) The contact element method with two relative coordinates has two main features: 1) The element meshing depends on the contact length between rolls or between the work roll and the strip, whose width may be identical or different; 2) Each element has two relative coordinates depending on the two contact objects.

(3) With the contact element method with two relative coordinates, a program code "Setup Models for Sendzimir
Mill" (SM4SM) has been developed to predict the strip profile for the Sendzimir mill with double AS-U-Roll systems. With the SM4SM, the strip profiles are predicted under various rolling conditions, such as the position of the AS-U racks, the 1st IMR shift and taper slope and length, the roll $\mathrm{J}$ profile, the strip reduction ratio, etc.

\section{Acknowledgements}

The authors gratefully acknowledge the financial supports from POSCO, the National Natural Science Foundation of China through Grant No. 50534020, and the State Basic Research Key Projects (973) of China through Grant No. 2006CB605208-1.

\section{Nomenclature}

$C_{S S}(\mathrm{I})$ : Relative coordinate of element I based on the roll $\mathrm{S}$ between the roll $\mathrm{S}$ and the strip

$C_{X Y}(\mathrm{I})$ : Relative coordinate of element I based on roll $\mathrm{X}$ between rolls $\mathrm{X}$ and $\mathrm{Y}$, such as $C_{S O}(\mathrm{I})$, $C_{O S}(\mathrm{I})$, etc.

$D_{X}\left(C_{X Y}(\mathrm{I})\right)$ : Deformation of roll $\mathrm{X}$ in $C_{X Y}(\mathrm{I})$ between rolls $\mathrm{X}$ and $\mathrm{Y}$, such as $D_{S}\left(C_{S O}(\mathrm{I})\right), D_{O}\left(C_{O S}(\mathrm{I})\right)$, etc.

$D_{S_{-} Q_{s S}}\left(C_{S O}(\mathrm{I})\right)$ : Deflection of roll $\mathrm{S}$ caused by $Q_{S S}$ in $\mathrm{SO}$ direction in $C_{S O}(\mathrm{I})$

$D_{X_{-} Q_{v v}}\left(C_{X Y}(\mathrm{I})\right)$ : Deflection of roll X caused by $Q_{x y}$ in XY direction in $C_{X Y}(\mathrm{I})$, such as $D_{S_{-} Q_{S O}}\left(C_{S O}(\mathrm{I})\right)$, $D_{S_{-} Q_{S P}}\left(C_{S O}(\mathrm{I})\right)$, etc. 
$E$ : Young's modulus

$F$ : Assembling force

$F_{X Y}(\mathrm{I})$ : Flattening of roll $\mathrm{X}$ under unit pressure between rolls $\mathrm{X}$ and $\mathrm{Y}$, such as $F_{S O}(\mathrm{I}), F_{O S}(\mathrm{I})$, etc.

$I_{X}$ : Inertia moment of roll $\mathrm{X}$, such as $I_{S}, I_{O}$, etc.

$L$ : Barrel length of roll

$l_{1}$ : Distance between the position of acting force and the roll end, $l_{2}=L-l_{1}$

$Q_{S S}(\mathrm{I})$ : Rolling pressure acting upon element in $C_{S S}(\mathrm{I})$ between the roll $\mathrm{S}$ and the strip

$Q_{X Y}(\mathrm{I})$ : Pressure acting upon element in $C_{X Y}(\mathrm{I})$ between rolls $\mathrm{X}$ and $\mathrm{Y}$, such as $Q_{S O}, Q_{O S}$, etc.

$R F_{X Y}\left(C_{X Y}(\mathrm{I})\right)$ : Flattening of roll $\mathrm{X}$ in $C_{X Y}(\mathrm{I})$ between rolls $\mathrm{X}$ and $\mathrm{Y}$, such as $R F_{S O}\left(C_{S O}(\mathrm{I})\right), R F_{O S}\left(C_{O S}(\mathrm{I})\right)$, etc.

$W_{S S}$ : Width of element between the strip and the work roll

$W_{X}$ : Barrel length of roll $\mathrm{X}$, such as $W_{S}, W_{O}$, etc.

$W_{X Y}$ : Width of element between rolls $\mathrm{X}$ and $\mathrm{Y}$, such as: $W_{S O}, W_{S P}$, etc.

$\alpha_{X}$ : Friction angle between rolls, such as: $\alpha_{A}, \alpha_{B}$, etc.

$\varphi_{X}:$ Angle between rolls center, such as: $\varphi_{A}, \varphi_{B}$, etc.

$\Phi_{X Y}:$ Combination of $W_{X}, I_{X}, C_{X Y}(\mathrm{I})$

$v$ : Angle between rolling force and line SJ

$\varepsilon:$ Strain

\section{REFERENCES}

1) A. Scheider and R. Werners: Iron Steel Eng., 76 (1999), 44.

2) K. Hara, T. Yamada and K. Takagi: ISIJ Int., 31 (1991), 607.

3) B. Berger, H. Schulte, M. Benfer and F. W. Rinke: Metall. Plant Technol. Int., 23 (2000), 70.

4) F. Peter, R. Jens and J. John: Iron Steel Eng., 76 (1999), 41.

5) K. Dutton: An Investigation into the Design and Performance of an Automatic Shape Control System for a Sendzimir Cold Rolling Mill, British Steel Corporation, Sheffield, (1983), 1.

6) G. W. D. M. Gunawardene: A Static Model of a Sendzimir Mill for Use in Shape Control, British Steel Corporation, Sheffield, (1982), 1.

7) T. H. Kim, W. H. Lee and S. M. Hwang: ISIJ Int., 43 (2003), 1947.

8) S. Zhou, J. Zhong and G. Liu: Steel Res., 71 (2000), 403.

9) J. Xu, J. Zhang, F. Zhang, X. Liu, G. Wang, X. He and L. Ba: J. Iron Steel Res., 15 (2003), 23.

10) Z. Y. Jiang, A. K. Tieu, X. M. Zhang, C. Lu and W. H. Sun: J. Mater. Process. Technol., 140 (2003), 542.

11) W. Y. D. Yuen, A. Duval and B. Wecher: Steel Rolling '98, ISIJ, Tokyo, (1998), 296.

12) Y. Liu and W. Lee: ISIJ Int., 45 (2005), 1173.

13) J. Li, X. Qi and J. Lian: J. Iron Steel Res. Int., 11 (2004), 32.

14) W. Wang and T. Liang: Mech. Sci. Technol., 21 (2002), 882.

15) M. Knapinski: J. Mater. Process. Technol., 175 (2006), 257.

16) X. Li, D. Sun, J. Lian, L. Yang and H. Liu: China Mech. Eng., 17 (2006), 279.

17) G. Wang: Strip Shape Control and Shape Theory, Metallurgical Industry Press, Beijing, (1986), 289.

18) Z. Y. Jiang, H. T. Zhu and A. K. Tieu: Int. J. Mech. Sci., 48 (2006), 697.

19) C. Pan: 20-High Mill and High Precise Cold Strip Rolling, Metallurgical Industry Press, Beijing, (2003), 224.

20) Q. Fan: Mechanical of Engineer, High Education Press, Beijing, (1989), 112.

\section{Appendix. Deformation Coordination Equations be- tween Rolls}

1) Between the Rolls $S$ and $P$

The deflection of the roll $\mathrm{S}$ is affected by $Q_{S S}, Q_{S O}$ and $Q_{S P}$, and the deflection of the roll $\mathrm{P}$ is affected by $Q_{S P}, Q_{P J}$ and $Q_{P K}$. Similar to Eq. (11), the deformation coordination equation between the rolls $\mathrm{S}$ and $\mathrm{P}$ is expressed by Eq. (12).

$$
\begin{aligned}
& \sum_{\mathrm{J}=1}^{\mathrm{N}}\left(Q_{S S}(\mathrm{~J}) \times W_{S S} \times \mathrm{g}\left(\cos \left(\varphi_{B}-v\right), C_{S S}(\mathrm{~J}), \Phi_{S P}\right)\right. \\
& +Q_{S O}(\mathrm{~J}) \times W_{S O} \times \mathrm{g}\left(-\cos \left(\varphi_{A}+\varphi_{B}-\alpha_{A}\right), C_{S O}(\mathrm{~J}), \Phi_{S P}\right) \\
& \left.+Q_{S P}(\mathrm{~J}) \times W_{S P} \times \mathrm{g}\left(-\cos \left(\alpha_{B}\right), C_{S P}(\mathrm{~J}), \Phi_{S P}\right)\right) \\
& +Q_{S P}(\mathrm{I}) \times F_{S P}(\mathrm{I}) \\
& =\sum_{\mathrm{J}=1}^{\mathrm{N}}\left(Q_{S P}(\mathrm{~J}) \times W_{S P} \times \mathrm{g}\left(\cos \left(\alpha_{B}\right), C_{P S}(\mathrm{~J}), \Phi_{P S}\right)\right. \\
& +Q_{P J}(\mathrm{~J}) \times W_{P J} \times \mathrm{g}\left(-\cos \left(\varphi_{E}-\alpha_{E}\right), C_{P J}(\mathrm{~J}), \Phi_{P S}\right) \\
& \left.+Q_{P K}(\mathrm{~J}) \times W_{P K} \times \mathrm{g}\left(-\cos \left(\varphi_{F}-\alpha_{F}\right), C_{P K}(\mathrm{~J}), \Phi_{S P}\right)\right) \\
& +Q_{S P}(\mathrm{I}) \times F_{P S}(\mathrm{I}) \quad(1 \leq \mathrm{I} \leq \mathrm{N}) \text {. }
\end{aligned}
$$

2) Between the Rolls $\mathrm{O}$ and $\mathrm{I}$

The deflection of the roll $\mathrm{O}$ is affected by $Q_{S O}, Q_{O I}$ and $Q_{O J}$, and the deflection of the roll $\mathrm{P}$ is affected by $Q_{O I}, Q_{I A}$ and $Q_{I B}$. The deformation coordination equation between the rolls $\mathrm{O}$ and $\mathrm{I}$ is expressed by Eq. (13).

$$
\begin{aligned}
& \sum_{\mathrm{J}=1}^{\mathrm{N}}\left(Q_{S O}(\mathrm{~J}) \times W_{S O} \times \mathrm{g}\left(\cos \left(\varphi_{C}+\alpha_{A}\right), C_{O S}(\mathrm{~J}), \Phi_{O I}\right)\right. \\
& +Q_{O I}(\mathrm{~J}) \times W_{O I} \times \mathrm{g}\left(-\cos \left(\alpha_{C}\right), C_{O I}(\mathrm{~J}), \Phi_{O I}\right) \\
& \left.+Q_{O J}(\mathrm{~J}) \times W_{O J} \times \mathrm{g}\left(-\cos \left(\varphi_{C}+\varphi_{D}+\alpha_{D}\right), C_{O J}(\mathrm{~J}), \Phi_{O I}\right)\right) \\
& +Q_{O I}(\mathrm{I}) \times F_{O I}(\mathrm{I}) \\
& =\sum_{\mathrm{J}=1}^{\mathrm{N}}\left(Q_{O I}(\mathrm{~J}) \times W_{O I} \times \mathrm{g}\left(\cos \left(\alpha_{C}\right), C_{I O}(\mathrm{~J}), \Phi_{I O}\right)\right. \\
& +Q_{I A}(\mathrm{~J}) \times W_{I A} \times \mathrm{g}\left(-\cos \left(\varphi_{G}+\alpha_{G}\right), C_{I A}(\mathrm{~J}), \Phi_{I O}\right) \\
& \left.+Q_{I B}(\mathrm{~J}) \times W_{I B} \times \mathrm{g}\left(-\cos \left(\varphi_{H}+\alpha_{H}\right), C_{I B}(\mathrm{~J}), \Phi_{I O}\right)\right) \\
& +Q_{O I}(\mathrm{I}) \times F_{I O}(\mathrm{I}) \quad(1 \leq \mathrm{I} \leq \mathrm{N})
\end{aligned}
$$

3) Between the Rolls $\mathrm{O}$ and $\mathrm{J}$

The deflection of the roll $\mathrm{O}$ is affected by $Q_{S O}, Q_{O I}$ and $Q_{O J}$, and the deflection of the roll $\mathrm{J}$ is affected by $Q_{O J}, Q_{P J}$, $Q_{J B}$ and $Q_{J C}$. The deformation coordination equation between the rolls $\mathrm{O}$ and $\mathrm{J}$ is expressed by Eq. (14).

$$
\begin{aligned}
\sum_{\mathrm{J}=1}^{\mathrm{N}}( & Q_{S O}(\mathrm{~J}) \times W_{S O} \times \mathrm{g}\left(\cos \left(\varphi_{D}-\alpha_{A}\right), C_{O S}(\mathrm{~J}), \Phi_{O J}\right) \\
& +Q_{O I}(\mathrm{~J}) \times W_{O I} \times \mathrm{g}\left(-\cos \left(\varphi_{C}+\varphi_{D}+\alpha_{C}\right), C_{O I}(\mathrm{~J}), \Phi_{O J}\right) \\
& \left.+Q_{O J}(\mathrm{~J}) \times W_{O J} \times \mathrm{g}\left(-\cos \left(\alpha_{D}\right), C_{O J}(\mathrm{~J}), \Phi_{O J}\right)\right) \\
& +Q_{O J}(\mathrm{I}) \times F_{O J}(\mathrm{I}) \\
= & \sum_{\mathrm{J}=1}^{\mathrm{N}}\left(Q_{O J}(\mathrm{~J}) \times W_{O J} \times \mathrm{g}\left(\cos \left(\alpha_{D}\right), C_{J O}(\mathrm{~J}), \Phi_{J O}\right)\right. \\
& +Q_{P J}(\mathrm{~J}) \times W_{P J} \\
& \times \mathrm{g}\left(\cos \left(\varphi_{D}-\varphi_{A}+\varphi_{E}-\varphi_{B}-\alpha_{E}\right), C_{J P}(\mathrm{~J}), \Phi_{J O}\right)
\end{aligned}
$$




$$
\begin{aligned}
& +Q_{J B}(\mathrm{~J}) \times W_{J B} \\
& \times \mathrm{g}\left(-\cos \left(\varphi_{I}+\alpha_{I}+\varphi_{D}-\varphi_{A}\right), C_{J B}(\mathrm{~J}), \Phi_{J O}\right) \\
& +Q_{J C}(\mathrm{~J}) \times W_{J C} \\
& \left.\times \mathrm{g}\left(-\cos \left(\varphi_{J}+\alpha_{J}-\varphi_{D}+\varphi_{A}\right), C_{J C}(\mathrm{~J}), \Phi_{J O}\right)\right) \\
& +Q_{O J}(\mathrm{I}) \times F_{J O}(\mathrm{I}) \quad(1 \leq \mathrm{I} \leq \mathrm{N})
\end{aligned}
$$

4) Between the Rolls P and J

The deflection of the roll $\mathrm{P}$ is affected by $Q_{S P}, Q_{P J}$ and $Q_{P K}$, and the deflection of the roll $\mathrm{J}$ is affected by $Q_{O J}, Q_{P J}$, $Q_{J B}$, and $Q_{J C}$. The deformation coordination equation between the rolls $\mathrm{P}$ and $\mathrm{J}$ is expressed by Eq. (15).

$$
\begin{aligned}
& \sum_{\mathrm{J}=1}\left(Q_{S P}(\mathrm{~J}) \times W_{S P} \times \mathrm{g}\left(\cos \left(\varphi_{E}+\alpha_{B}\right), C_{P S}(\mathrm{~J}), \Phi_{P J}\right)\right. \\
& +Q_{P J}(\mathrm{~J}) \times W_{P J} \times \mathrm{g}\left(-\cos \left(\alpha_{E}\right), C_{P J}(\mathrm{~J}), \Phi_{P J}\right) \\
& \left.+Q_{P K}(\mathrm{~J}) \times W_{P K} \times \mathrm{g}\left(-\cos \left(\varphi_{E}+\varphi_{F}-\alpha_{F}\right), C_{P K}(\mathrm{~J}), \Phi_{P J}\right)\right) \\
& +Q_{P J}(\mathrm{I}) \times F_{P J}(\mathrm{I}) \\
& =\sum_{\mathrm{J}=1}^{\mathrm{N}}\left(Q_{O J}(\mathrm{~J}) \times W_{O J}\right. \\
& \times \mathrm{g}\left(\cos \left(\varphi_{D}-\varphi_{A}+\varphi_{E}-\varphi_{B}+\alpha_{D}\right), C_{J O}(\mathrm{~J}), \Phi_{J P}\right) \\
& +Q_{P J}(\mathrm{~J}) \times W_{P J} \times \mathrm{g}\left(\cos \left(\alpha_{E}\right), C_{J P}(\mathrm{~J}), \Phi_{J P}\right) \\
& +Q_{J B}(\mathrm{~J}) \times W_{J B} \times \mathrm{g}\left(-\cos \left(\varphi_{I}+\alpha_{I}-\varphi_{D}+\varphi_{A}\right), C_{J B}(\mathrm{~J}), \Phi_{J P}\right) \\
& +Q_{J C}(\mathrm{~J}) \times W_{J C} \\
& \left.\times \mathrm{g}\left(-\cos \left(\varphi_{J}+\alpha_{J}+\varphi_{D}-\varphi_{A}\right), C_{J C}(\mathrm{~J}), \Phi_{J P}\right)\right) \\
& +Q_{P J}(\mathrm{I}) \times F_{J P}(\mathrm{I}) \quad(1 \leq \mathrm{I} \leq \mathrm{N}) \text {. }
\end{aligned}
$$

5) Between the Rolls $P$ and $K$

The deflection of the roll $\mathrm{P}$ is affected by $Q_{S P}, Q_{P J}$ and $Q_{P K}$, and the deflection of the roll $\mathrm{K}$ is affected by $Q_{P K}, Q_{K C}$ and $Q_{K D}$. The deformation coordination equation between the rolls $\mathrm{P}$ and $\mathrm{K}$ is expressed by Eq. (16).

$$
\begin{aligned}
& \sum_{\mathrm{J}=1}^{\mathrm{N}}\left(Q_{S P}(\mathrm{~J}) \times W_{S P} \times \mathrm{g}\left(\cos \left(\varphi_{F}-\alpha_{B}\right), C_{P S}(\mathrm{~J}), \Phi_{P K}\right)\right. \\
& +Q_{P J}(\mathrm{~J}) \times W_{P J} \times \mathrm{g}\left(-\cos \left(\varphi_{E}+\varphi_{F}-\alpha_{E}\right), C_{P J}(\mathrm{~J}), \Phi_{P K}\right) \\
& \left.+Q_{P K}(\mathrm{~J}) \times W_{P K} \times \mathrm{g}\left(-\cos \left(\alpha_{F}\right), C_{P K}(\mathrm{~J}), \Phi_{P K}\right)\right) \\
& +Q_{P K}(\mathrm{I}) \times F_{P K}(\mathrm{I}) \\
& =\sum_{\mathrm{J}=1}^{\mathrm{N}}\left(Q_{P K}(\mathrm{~J}) \times W_{P K} \times \mathrm{g}\left(\cos \left(\alpha_{F}\right), C_{K P}(\mathrm{~J}), \Phi_{K P}\right)\right. \\
& +Q_{K C}(\mathrm{~J}) \times W_{K C} \times \mathrm{g}\left(-\cos \left(\varphi_{K}+\alpha_{K}\right), C_{K C}(\mathrm{~J}), \Phi_{K P}\right) \\
& \left.+Q_{K D}(\mathrm{~J}) \times W_{K D} \times \mathrm{g}\left(-\cos \left(\varphi_{L}+\alpha_{L}\right), C_{K P}(\mathrm{~J}), \Phi_{K P}\right)\right) \\
& +Q_{P K}(\mathrm{I}) \times F_{K P}(\mathrm{I}) \quad(1 \leq \mathrm{I} \leq \mathrm{N}) .
\end{aligned}
$$

\section{6) Between the Rolls I and A}

In Fig. 2, the deflection of the roll I is affected by $Q_{O I}$, $Q_{I A}$ and $Q_{I B}$, and the deflection of the roll $\mathrm{A}$ is affected by $Q_{I A}$. The deformation coordination equation between the rolls I and A is expressed by Eq. (17).

$$
\begin{aligned}
\sum_{\mathrm{J}=1}^{\mathrm{N}} & \left(Q_{O I}(\mathrm{~J}) \times W_{O I} \times \mathrm{g}\left(\cos \left(\varphi_{G}-\alpha_{C}\right), C_{I O}(\mathrm{~J}), \Phi_{I A}\right)\right. \\
& +Q_{I A}(\mathrm{~J}) \times W_{I A} \times \mathrm{g}\left(-\cos \left(\alpha_{G}\right), C_{I A}(\mathrm{~J}), \Phi_{I A}\right) \\
& \left.+Q_{I B}(\mathrm{~J}) \times W_{I B} \times \mathrm{g}\left(-\cos \left(\varphi_{G}+\varphi_{H}-\alpha_{H}\right), C_{I B}(\mathrm{~J}), \Phi_{I A}\right)\right)
\end{aligned}
$$

$$
\begin{aligned}
& +Q_{I A}(\mathrm{I}) \times F_{I A}(\mathrm{I}) \\
= & \sum_{\mathrm{J}=1}^{\mathrm{N}} Q_{I A}(\mathrm{~J}) \times W_{I A} \times \mathrm{g}\left(\cos \left(\alpha_{G}\right), C_{A I}(\mathrm{~J}), \Phi_{A I}\right) \\
& +Q_{I A}(\mathrm{I}) \times F_{A I}(\mathrm{I}) \quad(1 \leq \mathrm{I} \leq \mathrm{N}) \ldots \ldots \ldots \ldots \ldots \ldots \ldots \ldots \ldots \ldots \ldots
\end{aligned}
$$

\section{7) Between the Rolls I and B}

The deflection of the roll I is affected by $Q_{O I}, Q_{I A}$ and $Q_{I B}$, and the deflection of the roll B is affected by $Q_{I B}$ and $Q_{J B}$. The deformation coordination equation between the rolls I and B is expressed by Eq. (18).

$$
\begin{aligned}
& \sum_{\mathrm{J}=1}^{\mathrm{N}}\left(Q_{O I}(\mathrm{~J}) \times W_{O I} \times \mathrm{g}\left(\cos \left(\varphi_{H}+\alpha_{C}\right), C_{I O}(\mathrm{~J}), \Phi_{I B}\right)\right. \\
& +Q_{I A}(\mathrm{~J}) \times W_{I A} \times \mathrm{g}\left(-\cos \left(\varphi_{G}+\varphi_{H}+\alpha_{G}\right), C_{I A}(\mathrm{~J}), \Phi_{I B}\right) \\
& \left.+Q_{I B}(\mathrm{~J}) \times W_{I B} \times \mathrm{g}\left(-\cos \left(\alpha_{H}\right), C_{I B}(\mathrm{~J}), \Phi_{I B}\right)\right) \\
& +Q_{I B}(\mathrm{I}) \times F_{I B}(\mathrm{I}) \\
& =\sum_{\mathrm{J}=1}^{\mathrm{N}}\left(Q_{I B}(\mathrm{~J}) \times W_{I B} \times \mathrm{g}\left(\cos \left(\alpha_{H}\right), C_{B I}(\mathrm{~J}), \Phi_{B I}\right)\right. \\
& +Q_{J B}(\mathrm{~J}) \times W_{J B} \\
& \left.\times \mathrm{g}\left(\cos \left(2 \varphi_{H}-\varphi_{C}-\varphi_{D}-\alpha_{G}\right), C_{B J}(\mathrm{~J}), \Phi_{B I}\right)\right) \\
& +Q_{I B}(\mathrm{I}) \times F_{B I}(\mathrm{I}) \quad(1 \leq \mathrm{I} \leq \mathrm{N}) \text {. }
\end{aligned}
$$

8) Between the Rolls J and B

The deflection of the roll $\mathrm{J}$ is affected by $Q_{O J}, Q_{P J}, Q_{J B}$ and $Q_{J C}$, and the deflection of the roll B is affected by $Q_{I B}$ and $Q_{J B}$. The deformation coordination equation between the rolls $\mathrm{J}$ and B is expressed by Eq. (19).

$$
\begin{aligned}
& \sum_{\mathrm{J}=1}^{\mathrm{N}}\left(Q_{O J}(\mathrm{~J}) \times W_{O J} \times \mathrm{g}\left(\cos \left(\varphi_{D}-\varphi_{A}+\varphi_{I}+\alpha_{D}\right), C_{J O}(\mathrm{~J}), \Phi_{J B}\right)\right. \\
& +Q_{P J}(\mathrm{~J}) \times W_{P J} \times \mathrm{g}\left(\cos \left(\varphi_{I}-\varphi_{E}+\varphi_{B}+\alpha_{E}\right), C_{J P}(\mathrm{~J}), \Phi_{J B}\right) \\
& +Q_{J B}(\mathrm{~J}) \times W_{J B} \times \mathrm{g}\left(-\cos \left(\alpha_{I}\right), C_{J B}(\mathrm{~J}), \Phi_{J B}\right) \\
& \left.+Q_{J C}(\mathrm{~J}) \times W_{J C} \times \mathrm{g}\left(-\cos \left(\varphi_{I}+\varphi_{J}-\alpha_{J}\right), C_{J C}(\mathrm{~J}), \Phi_{J B}\right)\right) \\
& +Q_{J B}(\mathrm{I}) \times F_{J B}(\mathrm{I}) \\
& =\sum_{\mathrm{J}=1}^{\mathrm{N}}\left(Q_{I B}(\mathrm{~J}) \times W_{I B}\right. \\
& \times \mathrm{g}\left(\cos \left(2 \varphi_{H}-\varphi_{C}-\varphi_{D}-\alpha_{H}\right), C_{B I}(\mathrm{~J}), \Phi_{B J}\right) \\
& \left.+Q_{J B}(\mathrm{~J}) \times W_{J B} \times \mathrm{g}\left(\cos \left(\alpha_{L}\right), C_{B J}(\mathrm{~J}), \Phi_{B J}\right)\right) \\
& +Q_{J B}(\mathrm{I}) \times F_{B J}(\mathrm{I}) \quad(1 \leq \mathrm{I} \leq \mathrm{N})
\end{aligned}
$$

9) Between the Rolls J and C

The deflection of the roll $\mathrm{J}$ is affected by $Q_{O J}, Q_{P J}, Q_{J B}$ and $Q_{J C}$, and the deflection of the roll $\mathrm{C}$ is affected by $Q_{J C}$ and $Q_{K C}$. The deformation coordination equation between the rolls $\mathrm{J}$ and $\mathrm{C}$ is expressed by Eq. (20).

$$
\begin{aligned}
\sum_{\mathrm{J}=1}^{\mathrm{N}} & \left(Q_{O J}(\mathrm{~J}) \times W_{O J} \times \mathrm{g}\left(\cos \left(\varphi_{I}-\varphi_{D}+\varphi_{A}-\alpha_{D}\right), C_{J O}(\mathrm{~J}), \Phi_{J C}\right)\right. \\
& +Q_{P J}(\mathrm{~J}) \times W_{P J} \times \mathrm{g}\left(\cos \left(\varphi_{I}+\varphi_{E}-\varphi_{B}-\alpha_{E}\right), C_{J P}(\mathrm{~J}), \Phi_{J C}\right) \\
& +Q_{J B}(\mathrm{~J}) \times W_{J B} \times \mathrm{g}\left(-\cos \left(\varphi_{I}+\varphi_{J}+\alpha_{I}\right), C_{J B}(\mathrm{~J}), \Phi_{J C}\right) \\
& \left.+Q_{J C}(\mathrm{~J}) \times W_{J C} \times \mathrm{g}\left(-\cos \left(\alpha_{J}\right), C_{J C}(\mathrm{~J}), \Phi_{J C}\right)\right) \\
& +Q_{J C}(\mathrm{I}) \times F_{J C}(\mathrm{I})
\end{aligned}
$$




$$
\begin{aligned}
& =\sum_{\mathrm{J}=1}^{\mathrm{N}}\left(Q_{J C}(\mathrm{~J}) \times W_{J C} \times \mathrm{g}\left(\cos \left(\alpha_{J}\right), C_{C J}(\mathrm{~J}), \Phi_{C J}\right)\right. \\
& +Q_{K C}(\mathrm{~J}) \times W_{K C} \\
& \left.\times \mathrm{g}\left(\cos \left(2 \varphi_{K}-\varphi_{E}-\varphi_{F}+\alpha_{L}\right), C_{C K}(\mathrm{~J}), \Phi_{C J}\right)\right) \\
& +Q_{J C}(\mathrm{I}) \times F_{C J}(\mathrm{I}) \quad(1 \leq \mathrm{I} \leq \mathrm{N}) .
\end{aligned}
$$

10) Between the Rolls $\mathrm{K}$ and $\mathrm{C}$

The deflection of the roll $\mathrm{K}$ is affected by $Q_{P K}, Q_{K C}$ and $Q_{K D}$, and the deflection of the roll C is affected by $Q_{J C}$ and $Q_{K C}$. The deformation coordination equation between the rolls $\mathrm{J}$ and $\mathrm{C}$ is expressed by Eq. (21).

$$
\begin{aligned}
\sum_{\mathrm{J}=1}^{\mathrm{N}} & \left(Q_{P K}(\mathrm{~J}) \times W_{P K} \times \mathrm{g}\left(\cos \left(\varphi_{K}-\alpha_{F}\right), C_{K P}(\mathrm{~J}), \Phi_{K C}\right)\right. \\
& +Q_{K C}(\mathrm{~J}) \times W_{K C} \times \mathrm{g}\left(-\cos \left(\alpha_{K}\right), C_{K C}(\mathrm{~J}), \Phi_{K C}\right) \\
& \left.+Q_{K D}(\mathrm{~J}) \times W_{K D} \times \mathrm{g}\left(-\cos \left(\varphi_{K}+\varphi_{L}-\alpha_{L}\right), C_{K D}(\mathrm{~J}), \Phi_{K C}\right)\right) \\
& +Q_{K C}(\mathrm{I}) \times F_{K C}(\mathrm{I}) \\
= & \sum_{\mathrm{J}=1}^{\mathrm{N}}\left(Q_{J C}(\mathrm{~J}) \times W_{J C}\right.
\end{aligned}
$$

$$
\begin{aligned}
& \times \mathrm{g}\left(\cos \left(2 \varphi_{K}-\varphi_{E}-\varphi_{F}+\alpha_{F}\right), C_{C J}(\mathrm{~J}), \Phi_{C K}\right) \\
& \left.+Q_{K C}(\mathrm{~J}) \times W_{K C} \times \mathrm{g}\left(\cos \left(\alpha_{K}\right), C_{C K}(\mathrm{~J}), \Phi_{C K}\right)\right) \\
& +Q_{K C}(\mathrm{I}) \times F_{C K}(\mathrm{I}) \quad(1 \leq \mathrm{I} \leq \mathrm{N}) .
\end{aligned}
$$

\section{1) Between the Rolls $K$ and $D$}

The deflection of the roll $\mathrm{K}$ is affected by $Q_{P K}, Q_{K C}$ and $Q_{K D}$, and the deflection of the roll $\mathrm{D}$ is affected by $Q_{K D}$. The deformation coordination equation between the rolls $\mathrm{J}$ and $\mathrm{C}$ is expressed by Eq. (22).

$$
\begin{aligned}
& \sum_{\mathrm{J}=1}^{\mathrm{N}}\left(Q_{P K}(\mathrm{~J}) \times W_{P K} \times \mathrm{g}\left(\cos \left(\varphi_{L}+\alpha_{F}\right), C_{K P}(\mathrm{~J}), \Phi_{K D}\right)\right. \\
& +Q_{K C}(\mathrm{~J}) \times W_{K C} \times \mathrm{g}\left(-\cos \left(\varphi_{K}+\varphi_{L}+\alpha_{K}\right), C_{K C}(\mathrm{~J}), \Phi_{K D}\right) \\
& \left.+Q_{K D}(\mathrm{~J}) \times W_{K D} \times \mathrm{g}\left(-\cos \left(\alpha_{L}\right), C_{K D}(\mathrm{~J}), \Phi_{K D}\right)\right) \\
& +Q_{K D}(\mathrm{I}) \times F_{K D}(\mathrm{I}) \\
& =\sum_{\mathrm{J}=1}^{\mathrm{N}} Q_{K D}(\mathrm{~J}) \times W_{K D} \times \mathrm{g}\left(\cos \left(\alpha_{L}\right), C_{D K}(\mathrm{~J}), \Phi_{D K}\right) \\
& +Q_{K D}(\mathrm{I}) \times F_{D K}(\mathrm{I}) \quad(1 \leq \mathrm{I} \leq \mathrm{N})
\end{aligned}
$$

